\title{
Development of Shunt Active Power Filter for Harmonic Reduction using Synchronous Reference Frame with Space Vector Pulse Width Modulation
}

Department of Electrical Engineering, Ahmadu Bello University, Zaria, Nigeria.

ABSTRACT: The work aims at development of Shunt Active Power Filter (SAPF) for harmonic reduction. The current harmonics are being caused by nonlinear characteristic of power electronics based equipments which increase power losses and in turn reduce power quality. Synchronous Reference Frame (SRF) was used as a control strategy and for reference harmonic current generation and Space Vector Pulse Width Modulation (SVPWM) was adopted as switching signal generation. With RL load under balanced input voltage condition, the developed SAPFSVPWM achieved a reduction of THD of $0.91 \%$ as compared to 25.60 before compensation. In addition, the developed SAPF- SVPWM model was compared with SAPF without compensation using RL load under unbalanced voltage and the result shows that the developed SVPWM achieved reduction in THD of $1.74 \%$ as compared to $26.68 \%$ after and before compensation. The developed SVPWM model was also compared with SPWM balanced and unbalanced voltage condition. The results show that SVPWM performed better than SPWM. All the results obtained are within IEEE 519 harmonics standard (i.e. THD less than 5\%) with nonlinear load under balanced and unbalanced voltage.

KEYWORDS: Shunt active filter, input voltage, harmonics, space vector pulse width modulation, nonlinear load.

[Received Nov. 12, 2018, Revised Nov. 01, 2019, Accepted March 23, 2020]

Print ISSN: 0189-9546 | Online ISSN: 2437-2110

\section{INTRODUCTION}

Power quality is a thing of concern in the field of power system engineering due to nonlinear characteristic of power electronics equipment such as electrical drives, compact fluorescent lamp, oven among others which inject harmonics into distribution system (Abijit et al., 2016; Chennia et al., 2014). Poor power factor, voltage flicker, bad voltage regulation, voltage sags and swells are some of the examples of the disturbances of power system engineering and this is a result of degradation of power quality caused by harmonics (Suresh et al., 2011; Akash et al., 2016). Harmonics also reduce the life span of electrical appliances and equipments which leads to significant economic losses in term of revenue (Suleiman et al., 2017).

The conventional harmonic reduction is passive power filter and easy way to reduce the harmonic current. However, the capability of Passive power filter to remove all the harmonic distortion point of coupling (PCC) is limited. Some of the drawbacks are bulkiness and frequency resonance with the inductor in the grid which increases the harmonics (Sindhu et al., 2015; Varaprasad et al., 2014).

In recent times Active Power Filters (APF) was introduced and accepted as one of the most common compensation method. APF are switch mode power electronics inverters for harmonic cancellation at PCC so that harmonics free load current is supply to the consumers at PCC (Akash et al., 2016). The strategies use to obtain the reference signal, current controller, the system topology and DC-link voltage determine the effectiveness of shunt active power filter (SAPF) (Chennia et al., 2014; Akash et al., 2015).

Synchronous reference frame (d-q-o) theory, instantaneous real-reactive power (p-q) theory, modified instantaneous ( $\mathrm{p}-\mathrm{q})$ theory; flux-based controller; notch filter and Artificial Neural Network (ANN) are some of the different harmonics current signal generation strategies that have been used in the literature. (Zahira et al., 2011). Synchronous Reference Frame (SRF) theory widely used for reference signal generation owing to its directness, accuracy and dynamics compared others many methods (Abijit et al., 2016).

Similarly, hysteresis, triangular wave control, dead beat control, Space vector pulse width modulation among others have been established in the literature for switching signal generation (Naresh et al., 2012). Space Vector Pulse Width Modulation (SVPWM) is known for its complexity and higher with rigorous mathematical calculation for switching signal generation (Phuong 2012). SVPWM is one of the best in pulse signal generation because of advantages of low switching loss, wide range of modulation index and less harmonics distortion. It uses the DC link voltage more effectively than others technique (Phuong 2012).

This work presents the design of Shunt Active Power Filter (SAPF) for harmonic reduction. Synchronous reference frame is used for reference signal generation. Space Vector 
Pulse Width Modulation (SVPWM) is used for switching pulse generation. The paper is organized as follows: section one introduce the concept of SAPF, section two details the mathematical equations of SAPF and SVPWM. Section three details the design procedure and implementation, while section four present the results and discussed of the obtained results and section five details the conclusion of SAPF.

\section{SHUNT ACTIVE POWER FILTER (SAPF)}

An idea of active power filters is to improve the power factor that is caused by consumption of reactive power and to reduce harmonic current in the power supply. (Nalini et al., 2011). The shunt active power filter works by feeding the exert harmonics current extracted in the opposing direction to the grid at PCC. The achievement of active power filter hinged on the method used to generate reference current and the switching method used to control the inverter legs Chelli et al., 2015). The basic configuration of a shunt active filter is shown in Figure 1.

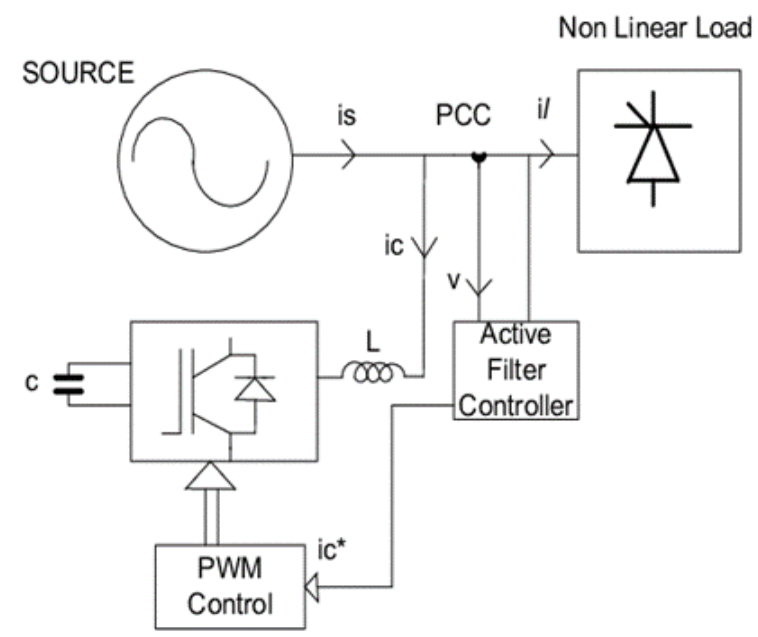

Figure 1: Basic Configuration of a SAPF (Abdeldjabbar et al. 2017)

\section{A. Synchronous Reference Frame $(d-q)$}

The $d-q$ theory transforms three phase voltage and current in $a-b-c$ quantities into $d-q$ in $d c$ quantities (Balasubramaniam et al., 2014). Synchronous reference frame (d-q-0) theory transform from a-b-c to $(\alpha-\beta)$ using Clark transformation equation and then transform from $(\alpha-\beta)$ to $(d-$ q-0) using park transformation equation (Hemachandra et al., 2015). The transformation equation is given as follows (Sunitha et al., 2013).

$$
\left[\begin{array}{l}
\mathrm{i}_{\mathrm{d}} \\
\mathrm{i}_{\mathrm{q}} \\
\mathrm{i}_{0}
\end{array}\right]=\sqrt{\frac{2}{3}}\left[\begin{array}{ccc}
\cos \theta & \cos (\theta-120) & \cos (\theta+120) \\
-\sin \theta & -\sin (\theta-120) & -\sin (\theta+120) \\
1 / \sqrt{2} & 1 / \sqrt{2} & 1 / \sqrt{2}
\end{array}\right]\left[\begin{array}{l}
\mathrm{i}_{\mathrm{a}} \\
\mathrm{i}_{\mathrm{b}} \\
\mathrm{i}_{\mathrm{c}}
\end{array}\right]
$$

\section{B. Concept of Space Vector Pulse Width Modulation}

Space vector pulse width modulation consists of six actives sector and two non-actives sector with reference voltage vector which moves round the states vector. Figure 2 shows the reference vector in the first sector (Phuong, 2012).

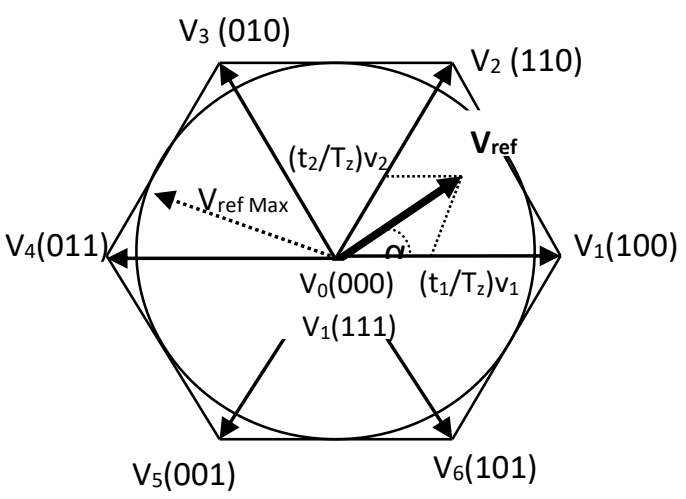

Figure 2: Space Vectors of Three-Phase Bridge Diagram (Thamizhazhagan et al., 2015).

The diagram of a three-phase bridge inverter is shown in the Figure 3. The upper transistors, and determine the current output voltage (Kumar et al., 2012).

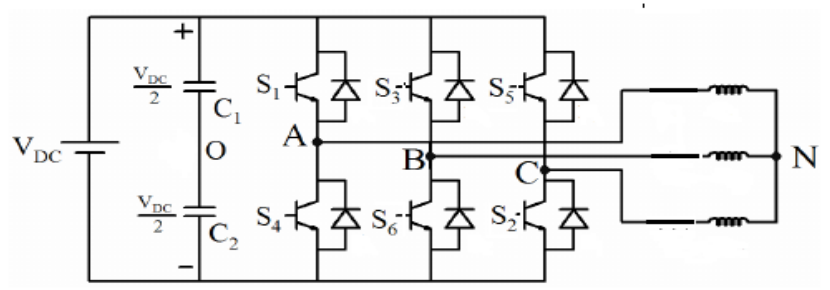

Figure 3: Three Phase Inverter Block Diagram (Phuong, 2012).

Figure 4 shows the eight switching configuration of a threephase inverter (Kumar et al., 2015).
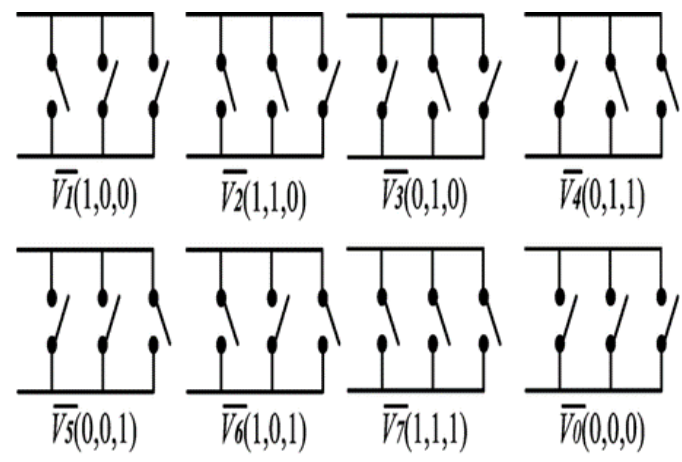

Figure 4: Inverter States (Priyanka et al., 2017).

When the reference voltage vector passes through each sector, different sets of switches in Table 1 will be turned on or off (Phuong, 2012). 
Table 1: Space vectors, switching states, and on-state switches (Phuong, 2012).

\begin{tabular}{|c|c|c|l|}
\hline $\begin{array}{c}\text { Space } \\
\text { Vector }\end{array}$ & $\begin{array}{c}\text { Switching } \\
\text { State }\end{array}$ & $\begin{array}{c}\text { On-state } \\
\text { Switch }\end{array}$ & Vector Definition \\
\hline $\overrightarrow{\mathrm{V}_{0}}$ & {$[000]$} & $\mathrm{S} 4, \mathrm{~S} 6, \mathrm{~S} 2$ & $\overrightarrow{\mathrm{V}}_{0}=0$ \\
\hline $\overrightarrow{\mathrm{V}_{1}}$ & {$[100]$} & $\mathrm{S} 1, \mathrm{~S} 6, \mathrm{~S} 2$ & $\overrightarrow{\mathrm{V}}_{1}=\frac{2}{3} \mathrm{~V}_{\mathrm{dc}} \mathrm{e}^{\mathrm{j} 0}$ \\
\hline $\overrightarrow{\mathrm{V}_{2}}$ & {$[110]$} & $\mathrm{S} 1, \mathrm{~S} 3, \mathrm{~S} 2$ & $\overrightarrow{\mathrm{V}}_{2}=\frac{2}{3} \mathrm{~V}_{\mathrm{dc}} \mathrm{e}^{\mathrm{j} \frac{\pi}{3}}$ \\
\hline $\overrightarrow{\mathrm{V}}_{3}$ & {$[010]$} & $\mathrm{S} 4, \mathrm{~S} 3, \mathrm{~S} 2$ & $\overrightarrow{\mathrm{V}}_{3}=\frac{2}{3} \mathrm{~V}_{\mathrm{dc}} \mathrm{e}^{\mathrm{j} \frac{2 \pi}{3}}$ \\
\hline $\overrightarrow{\mathrm{V}}_{4}$ & {$[011]$} & $\mathrm{S} 4, \mathrm{~S} 3, \mathrm{~S} 5$ & $\overrightarrow{\mathrm{V}}_{4}=\frac{2}{3} \mathrm{~V}_{\mathrm{dc}} \mathrm{e}^{\mathrm{j} \frac{3 \pi}{3}}$ \\
\hline $\overrightarrow{\mathrm{V}}_{5}$ & {$[001]$} & $\mathrm{S} 4, \mathrm{~S} 6, \mathrm{~S} 5$ & $\overrightarrow{\mathrm{V}}_{5}=\frac{2}{3} \mathrm{~V}_{\mathrm{dc}} \mathrm{e}^{\mathrm{j} \frac{4 \pi}{3}}$ \\
\hline $\overrightarrow{\mathrm{V}}_{6}$ & {$[101]$} & $\mathrm{S} 1, \mathrm{~S} 6, \mathrm{~S} 5$ & $\overrightarrow{\mathrm{V}}_{6}=\frac{2}{3} \mathrm{~V}_{\mathrm{dc}} \mathrm{e}^{\mathrm{j} \frac{5 \pi}{3}}$ \\
\hline $\overrightarrow{\mathrm{V}}_{7}$ & {$[111]$} & $\mathrm{S} 1, \mathrm{~S} 3, \mathrm{~S} 5$ & $\overrightarrow{\mathrm{V}}_{7}=\frac{2}{3} \mathrm{~V}_{\mathrm{dc}} \mathrm{e}^{\mathrm{j} \frac{6 \pi}{3}}$ \\
\hline
\end{tabular}

The line-to-line voltage vector is given as follows (Irfan et al., 2016).

$$
\left[\begin{array}{c}
\mathrm{V}_{\mathrm{ab}} \\
\mathrm{V}_{\mathrm{bc}} \\
\mathrm{V}_{\mathrm{ca}}
\end{array}\right]=\mathrm{V}_{\mathrm{dc}}\left[\begin{array}{ccc}
1 & -1 & 0 \\
0 & 1 & -1 \\
-1 & 0 & 1
\end{array}\right]\left[\begin{array}{l}
\mathrm{a} \\
\mathrm{b} \\
\mathrm{c}
\end{array}\right]
$$

Also, the phase voltage vector can be expressed as follows (Irfan et al., 2016).

$$
\left[\begin{array}{c}
\mathrm{V}_{\mathrm{an}} \\
\mathrm{V}_{\mathrm{bn}} \\
\mathrm{V}_{\mathrm{cn}}
\end{array}\right]=\frac{\mathrm{V}_{\mathrm{dc}}}{3}\left[\begin{array}{ccc}
2 & -1 & -1 \\
-1 & 2 & -1 \\
-1 & -1 & 2
\end{array}\right]\left[\begin{array}{l}
\mathrm{a} \\
\mathrm{b} \\
\mathrm{c}
\end{array}\right]
$$

\section{SYSTEM DESIGN AND MODELLING}

\section{A. Selection of DC Voltage}

The minimum value of Vdc was calculated using eqn (4).

$\mathrm{V}_{\mathrm{dc}} \geq \sqrt{3} \mathrm{Vpcc}-\max$

Vpcc-max $=400 \mathrm{~V}$

The required minimum of $V_{d c}$ was calculated to be $693 \mathrm{~V}$. Therefore, $700 \mathrm{~V}$ was chosen.

\section{B. Selection of Coupling Inductor}

The minimum value of interfacing inductor was calculated using eqn (5).

$$
\text { Lf } \geq \frac{\mathrm{V}_{\mathrm{dc}}}{12 \mathrm{fsw}_{\mathrm{f}-\max }}
$$

The converter maximum ripple current $=10 \mathrm{~A}$

$V_{d c}=693 \mathrm{~V}($ for modulation index $=1.7)$

Switching frequency $=20 \mathrm{kHz}$.

The minimum value of $\mathrm{L}_{\mathrm{f}}$ was calculated to be $2.88 \mathrm{mH}$. Therefore, $3 \mathrm{mH}$ was chosen.

\section{Selection of DC Capacitor}

The minimum value of DC capacitor was calculated using eqn (6).

$$
\mathrm{C}_{\mathrm{dc}}=\frac{\text { 2S.n.T }}{\mathrm{V}_{\mathrm{dc}-\max }^{2}-\mathrm{V}_{\mathrm{dc}-\min }^{2}}=\frac{\text { 2S.n.T }}{\left\{(1+\mathrm{z}) \mathrm{V}_{\mathrm{dc}}\right\}^{2}-\left\{(1-\mathrm{z}) \mathrm{V}_{\mathrm{dc}}\right\}^{2}}=\frac{\text { S.n.T }}{2 \mathrm{zV}_{\mathrm{dc}}^{2}}
$$

The allowable compensator power transfer is $20 \mathrm{kVA}$

Number of cycle, $n=0.5$ (i.e half cycle)

Period, T for one complete cycle is $0.02 \mathrm{~s}$

Change in $V_{d c}$ of $10 \%$ (i.e. $\mathrm{z}=0.1$ )

$V_{d c}=693 \mathrm{~V}($ for modulation index $=1.7$ )

The minimum capacity of Cdc was calculated to be $2082 \mu \mathrm{F}$. Therefore, $3000 \mu \mathrm{F}$ was chosen.

D. Shunt Active Power Filter Modeling in $d-q$ The SRF method is implemented by transforming the threephase source $V_{a}, V_{b}$ and $V_{c}$ and load current $\mathrm{i}_{\mathrm{a}}, \mathrm{i}_{\mathrm{b}}$, and $\mathrm{i}_{\mathrm{c}}$ into the three-phase (d-q-0) synchronous reference frame in dc quantities as expressed as follows (Mohammed, 2012).

$$
\begin{aligned}
& \mathrm{L}_{\mathrm{f}} \frac{\mathrm{di}}{\mathrm{dt}}=\mathrm{V}_{\mathrm{fa}}-\mathrm{R}_{\mathrm{f}} \mathbf{i}_{\mathrm{fa}}-\mathrm{V}_{\mathrm{sa}} \\
& \mathrm{L}_{\mathrm{f}} \frac{\mathrm{di} \mathrm{i}_{\mathrm{b}}}{\mathrm{dt}}=\mathrm{V}_{\mathrm{fb}}-\mathrm{R}_{\mathrm{f}} \mathbf{i}_{\mathrm{fb}}-\mathrm{V}_{\mathrm{sb}} \\
& \mathrm{L}_{\mathrm{f}} \frac{\mathrm{di} \mathrm{i}_{\mathrm{c}}}{\mathrm{dt}}=\mathrm{V}_{\mathrm{fc}}-\mathrm{R}_{\mathrm{f}} \mathbf{i}_{\mathrm{fc}}-\mathrm{V}_{\mathrm{sc}}
\end{aligned}
$$

Eqns (5) to (7) are transformed to synchronous reference frame using equation as expressed as follows:

$$
\begin{aligned}
& \mathrm{L}_{\mathrm{f}} \frac{\mathrm{di}}{\mathrm{dt}}=\mathrm{V}_{\mathrm{fd}}-\mathrm{V}_{\mathrm{sd}}-\mathrm{R}_{\mathrm{f}} \mathrm{i}_{\mathrm{fd}}-\mathrm{L}_{\mathrm{f}} \omega \mathrm{i}_{\mathrm{fq}} \\
& \mathrm{L}_{\mathrm{f}} \frac{\mathrm{di} \mathrm{i}_{\mathrm{fq}}}{\mathrm{dt}}=\mathrm{V}_{\mathrm{fq}}-\mathrm{V}_{\mathrm{sq}}-\mathrm{R}_{\mathrm{f}} \mathrm{i}_{\mathrm{fq}}+\mathrm{L}_{\mathrm{f}} \omega \mathrm{i}_{\mathrm{fd}}
\end{aligned}
$$

The currents on the axes $\mathrm{d}$ and $\mathrm{q}$ are decoupled into two components as follows: 


$$
\begin{aligned}
& U_{d}=L_{f} \frac{d i_{f d}}{d t}+R_{f} i_{f d} \\
& U_{q}=L_{f} \frac{d i_{f q}}{d t}+R_{f} i_{f q}
\end{aligned}
$$

Therefore, equation 10 and 11 is re-written as expressed as follows:

$$
\begin{aligned}
& \mathrm{V}_{\mathrm{fd}}^{*}=\mathrm{U}_{\mathrm{d}}+\mathrm{V}_{\mathrm{sd}}+\mathrm{L}_{\mathrm{f}} \omega \mathrm{i}_{\mathrm{fq}} \\
& \mathrm{V}_{\mathrm{fq}}^{*}=\mathrm{U}_{\mathrm{q}}+\mathrm{V}_{\mathrm{sq}}+\mathrm{L}_{\mathrm{f}} \omega \mathrm{i}_{\mathrm{fd}}
\end{aligned}
$$

Eqns (12) and (13) are therefore modeled in Matlab/Simulink.

\section{E. Design of Space Vector Pulse Width Modulation}

Space vector pulse width modulation can be implemented by the following steps (Jin-Woo, 2005):

(i) Determination of $V_{d}, V_{q}, V_{\text {ref }}$ and angle $\alpha$

(ii) Determination of time duration $T_{0}, T_{1}$ and $T_{2}$

(iii) Transistors switching time determination

\section{1.) Determination $\backslash$ of $V_{d}, V_{q}, V_{\text {ref }}$ and Angle $\alpha$}

Determination of $V_{d}, V_{q}, V_{\text {ref }}$ and angle $\alpha$ is derived as follows (Jin-Woo, 2005). Consider the sector 1 of the space vector hexagonal diagram in Figure 5.

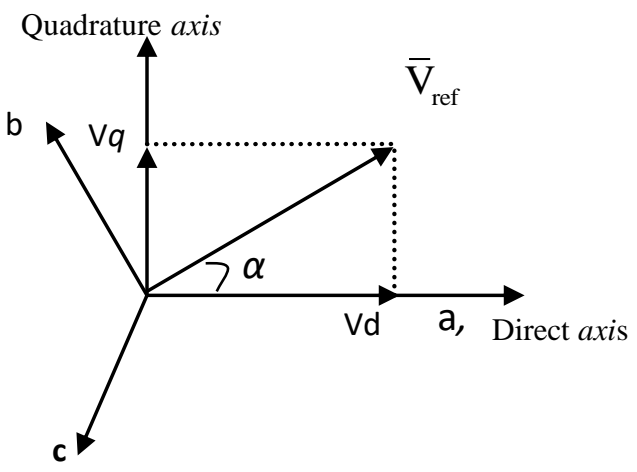

Figure 5: Space Vector in (d- q) Component.

Direct voltage equation and quadrature voltage equation can be written as follows:

$\mathrm{V}_{\mathrm{d}}=\mathrm{V}_{\mathrm{a}-\mathrm{n}}-\mathrm{V}_{\mathrm{b}-\mathrm{n}} \cos 60-\mathrm{V}_{\mathrm{c}-\mathrm{n}} \cos 60$

$\mathrm{V}_{\mathrm{q}}=0+\mathrm{V}_{\mathrm{b}-\mathrm{n}} \cos 30-\mathrm{V}_{\mathrm{c}-\mathrm{n}} \cos 30$

Eqns (14) and (15) are also expressed as follows:

$$
\left[\begin{array}{c}
\mathrm{V}_{\mathrm{d}} \\
\mathrm{V}_{\mathrm{q}}
\end{array}\right]=\frac{2}{3}\left[\begin{array}{ccc}
1 & -\frac{1}{2} & -\frac{1}{2} \\
0 & \frac{\sqrt{3}}{2} & -\frac{\sqrt{3}}{2}
\end{array}\right]
$$

Also equation of the alpha voltage and beta voltage is given as follows:

$$
\left[\begin{array}{c}
\mathrm{V}_{\alpha} \\
\mathrm{V}_{\beta}
\end{array}\right]=\left[\begin{array}{cc}
\cos \theta & -\sin \theta \\
\sin \theta & \cos \theta
\end{array}\right]
$$

Therefore, reference voltage equation and alpha angle are writing as follows:

$$
\begin{aligned}
& \left|\mathrm{V}_{\text {ref }}\right|=\sqrt{\mathrm{V}_{\alpha}^{2}+\mathrm{V}_{\beta}^{2}} \\
& \alpha=\tan ^{-1}\left(\frac{\mathrm{V}_{\alpha}}{\mathrm{V}_{\beta}}\right)=\omega \mathrm{t}
\end{aligned}
$$

where $\alpha$ is the angle between reference voltage and alpha voltage.

Eqns (14), (15), (18) and (19) were written as algorithm in Matlab function in Matlab function block in Matlab/Simulink to calculate $V_{d}, V_{q}, V_{\text {ref }}$ and angle $\alpha$.

2.) Determination of time duration $T_{0}, T_{1}$ and $T_{2}$

Consider the sector 1 of the space vector hexagonal diagram in Figure 6 (Naresh et al., 2012). The procedures for determining the switching time $T_{0}, T_{1}$ and $T_{2}$ is illustrated as follows (Tej et al., 2014; Raul, 2014).

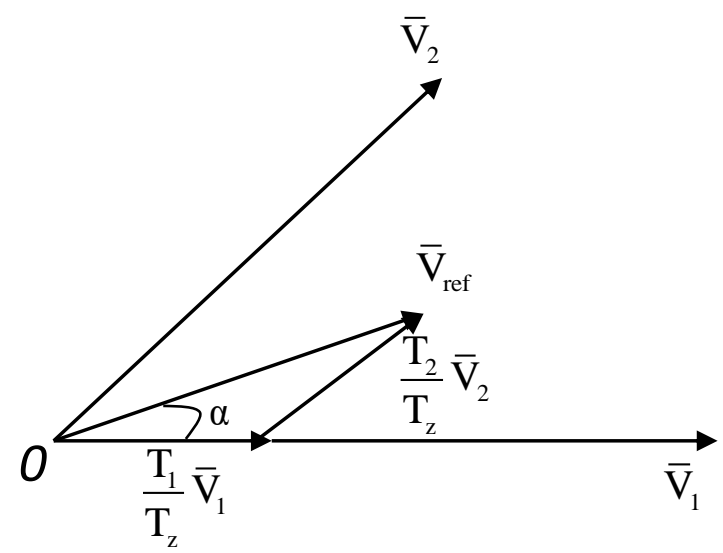

Figure 6: Reference Vector at Sector 1 (Naresh et al., 2012).

The time of switching at any sector is therefore written as follows:

$$
\begin{aligned}
& \mathrm{T}_{1}=\frac{\sqrt{3} \mathrm{~T}_{\mathrm{z}}\left|\overline{\mathrm{V}}_{\mathrm{ref}}\right|}{\mathrm{V}_{\mathrm{dc}}}\left(\sin \frac{\mathrm{n}}{3} \pi \cos \alpha-\cos \frac{\mathrm{n}}{3} \pi \sin \alpha\right) \\
& \mathrm{T}_{2}=\frac{\sqrt{3} \mathrm{~T}_{\mathrm{z}}\left|\overline{\mathrm{V}}_{\mathrm{ref}}\right|}{\mathrm{V}_{\mathrm{dc}}}\left(\sin \left(\alpha-\frac{\mathrm{n}-1}{3} \pi\right)\right) \\
& \mathrm{T}_{0}=\mathrm{T}_{\mathrm{z}}-\mathrm{T}_{1}-\mathrm{T}_{2}
\end{aligned}
$$

where,

$$
n=1 \text { (i.e. sector } 1-6) \quad 0 \leq \alpha \leq 60
$$

Eqns (20), (21) and (22) will be written as algorithm in Matlab function in Matlab/Simulink for sector identification and to calculate $T_{0}, T_{1}$ and $T_{2}$. 


\section{3.) Transistors switching time determination}

The switching pattern of each transistor $\left(\mathrm{S}_{1}-\mathrm{S}_{6}\right)$ of the voltage source inverter is therefore configured as shown in Figure 7

(Dev, 2015).

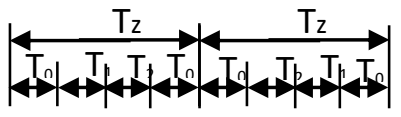

Up

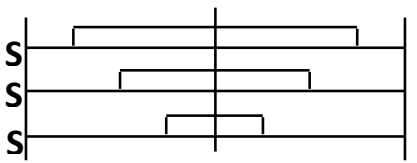

Lo
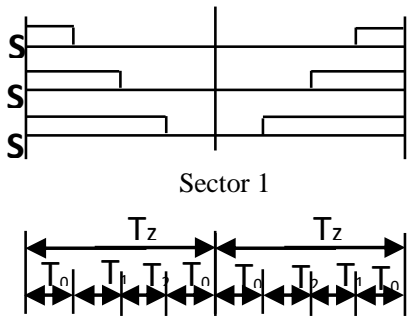

Up

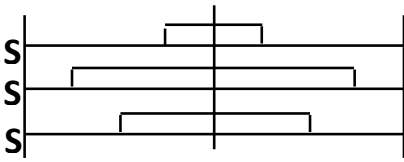

Lo

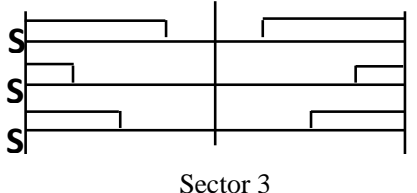

Sector 3

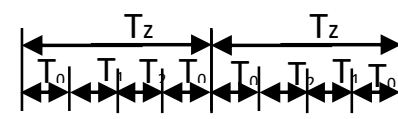

Up

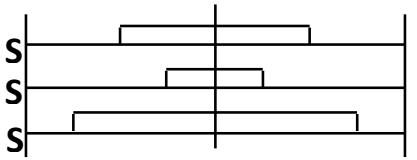

Lo

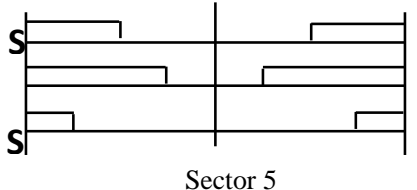

Up

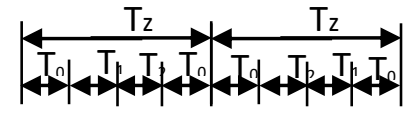

Lo

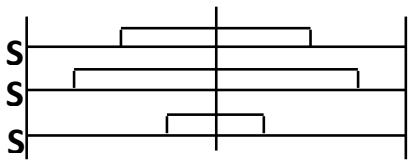

o

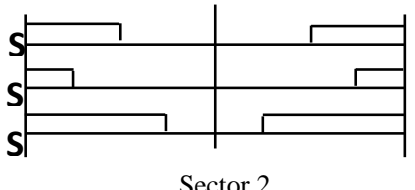

Up

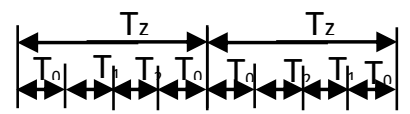

Lo
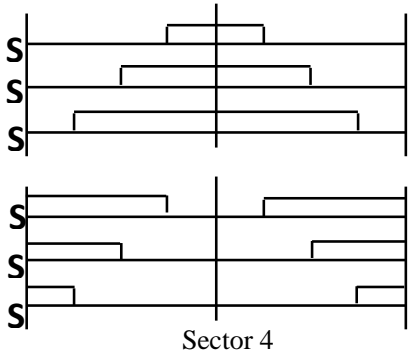

Up

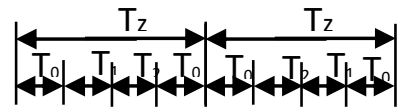

Lo
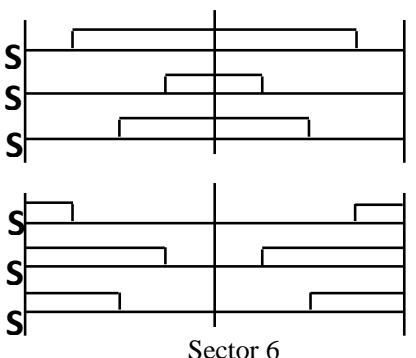

Figure 7: Time of Switching at each Sector Patterns.

\section{RESULTS AND DISCUSSION}

\section{A. Simulation of RL Load Balanced Loads}

Figure 8 shows the waveforms before compensation and after compensation. Figure 8 shows that source current is not an ideal sinusoidal and out of phase with input voltage due to the harmonic current generated by the RL load. The developed SAPF model was tested with RL balanced load condition. Figures 9 shows the simulation waveforms of input Voltage (Vs), Source Current (Is), Compensation Current (Ic) and DC Bus Voltage $\left(\mathrm{V}_{\mathrm{dc}}\right)$. The results show that, the source current $(I s)$ is now an ideal sinusoidal and rotates with the same angle

with input voltage $(V s)$ when compared with the waveform in Figure 8. The result also shows the waveform of compensation current (Ic) injected at the PCC in equal opposing direction to cancel the harmonics present in the load current. The reference DC bus voltage was maintained at 700 $\mathrm{V}$.
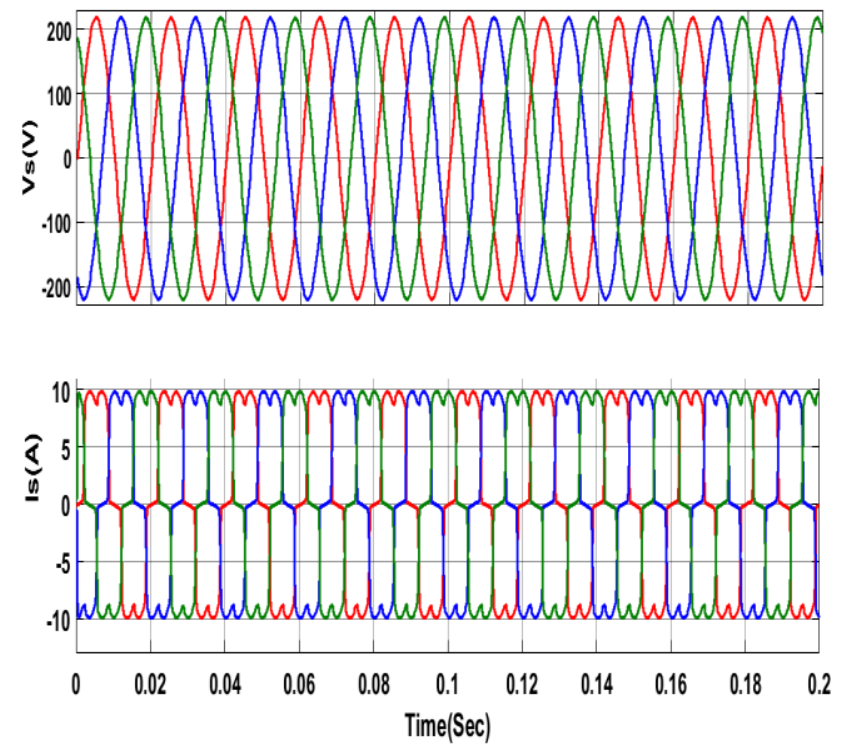

Figure 8: Waveforms of RL Load: Input Voltage (Vs), Source Current before Compensation.
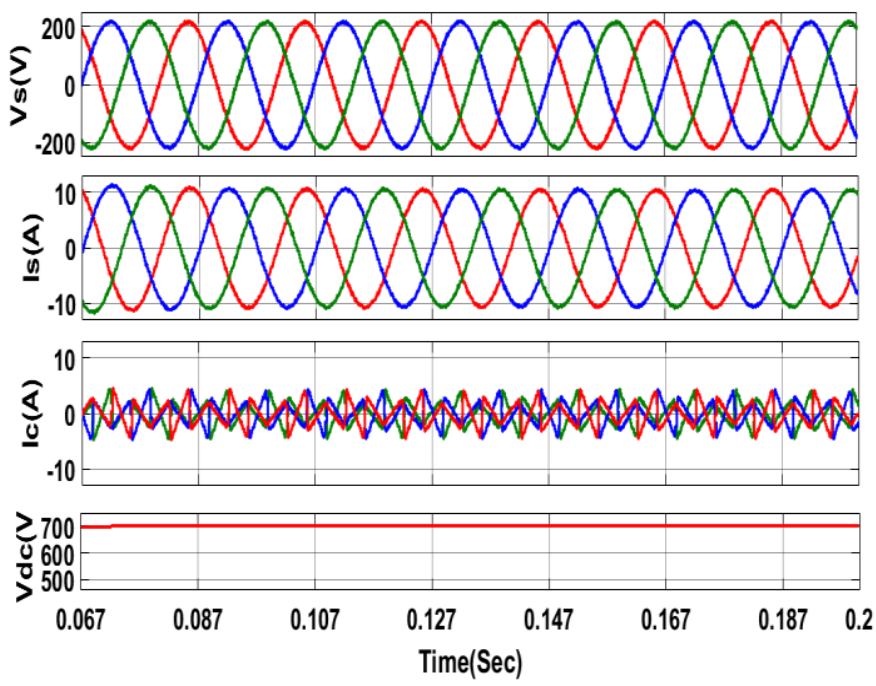

Figure 9: Simulation Waveform of RL Load with SVPWM: Input Voltage (Vs), Source Current (Is) after Compensation, Compensation Current (Ic) and DC Bus Voltage $\left(V_{d c}\right)$.

\section{B. Result of FFT Analysis of RL Load (Balanced Voltage)}

Figure 10 shows the Fast Fourier Transformation (FFT) analysis of load current before compensation. The THD obtained in Figure 10 is $25.60 \%$ and the fundamental $(50 \mathrm{~Hz})$ value is $10.4 \mathrm{~A}$. This THD value is large when compared with the IEEE standard harmonic limit (i.e < 5\%). The developed SAPF model was subjected to Fast Fourier Transformation (FFT) analysis under balanced voltage with SVPWM. The 
result obtained in Figure 11 shows the Fast Fourier Transformation (FFT) analysis of load current after compensation. The result shows a significant $0.91 \%$ reduction of THD when compared to $25.6 \%$ in Figure 10 . Figure 12 shows the Fast Fourier Transformation (FFT) analysis of load current after compensation with SPWM. The result is within the range of IEEE harmonic standard limit of $5 \%$.

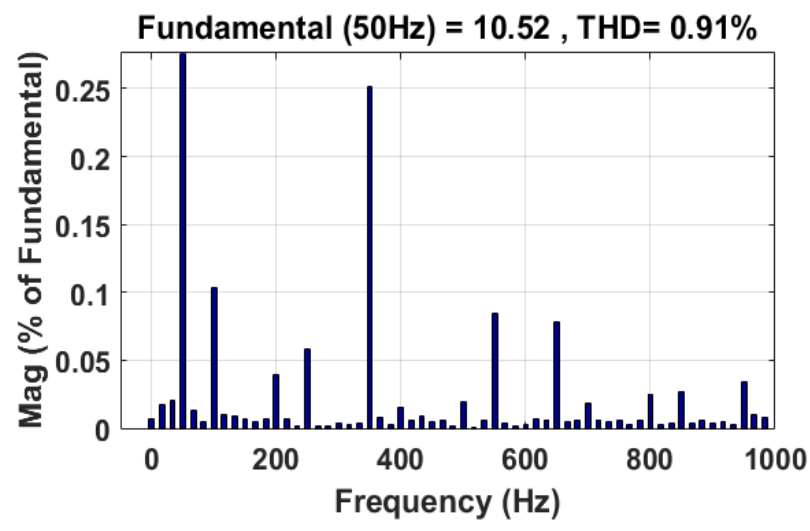

Figure 10: FFT Analysis of Source Current (Is) with RL Load before Compensation.

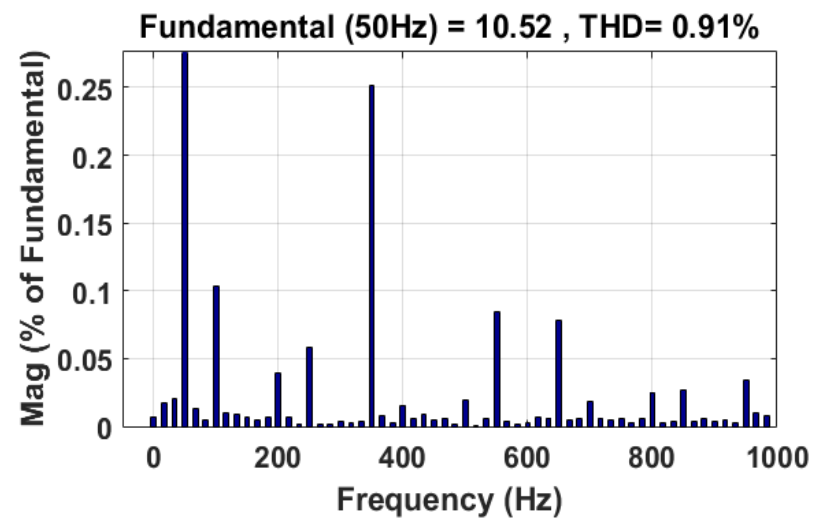

Figure 11: FFT Analysis of Source Current (Is) with RL Load after Compensation.

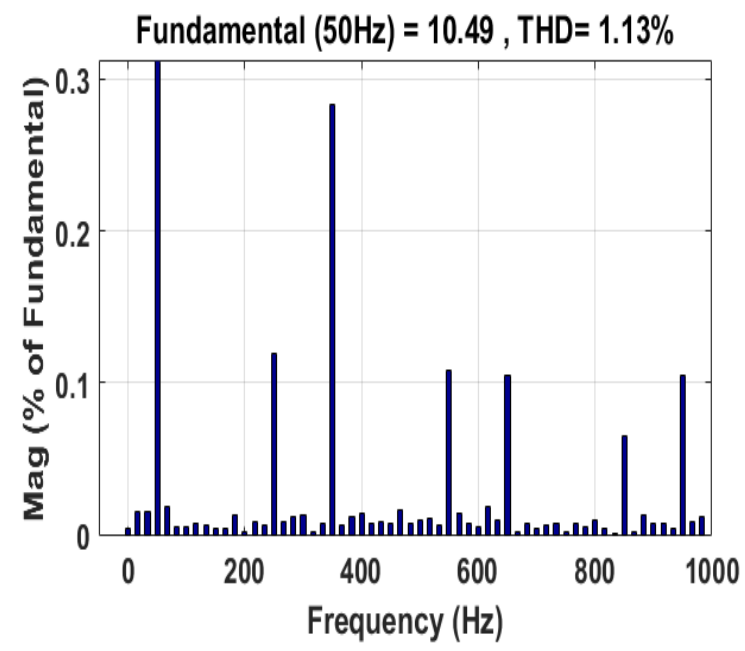

Figure 12: FFT Analysis of Source Current (Is) with RL Load after Compensation.

\section{B. Simulation Result of RL Load}

The developed SAPF model was tested with unbalanced input voltage of $V_{A}=200 \mathrm{~V}, V_{B}=210 \mathrm{~V}, V_{C}=220 \mathrm{~V}$. Figure 13 shows the waveforms before compensation and after compensation. The waveform of the simulation Figure 13 shows that source current is not an ideal sinusoidal due to the harmonic current generated by the combination of RL load and unbalanced voltage. The developed SAPF model was tested with RL balanced load condition. Figures 14 shows simulation waveforms of input Voltage (Vs), Source Current (Is), Compensation Current (Ic) and DC Bus Voltage $\left(\mathrm{V}_{\mathrm{dc}}\right)$. The results show that, the source current $(I s)$ is now sinusoidal and rotates with the same angle with the input voltage $(V s)$ when compared with Figure 13. The result also shows the waveform of compensation current (Ic) injected at the PCC and the DC bus voltage $(V d c)$. The reference DC bus voltage was maintained constant at $700 \mathrm{~V}$.
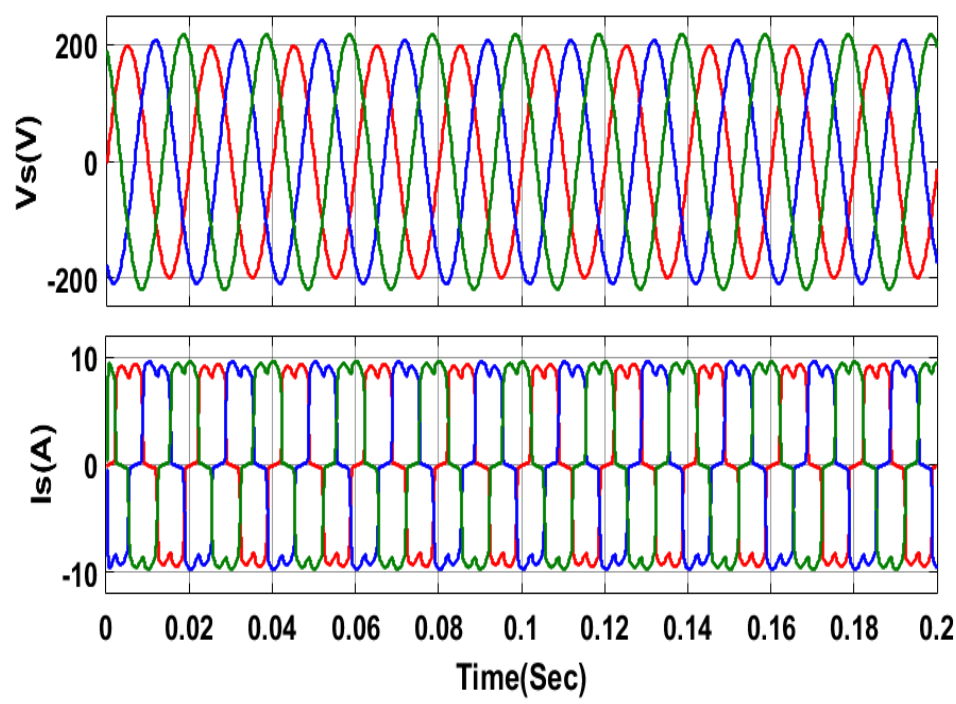

Figure 13: Waveforms of RL Load: Input Voltage (Vs), Source Current before Compensation.
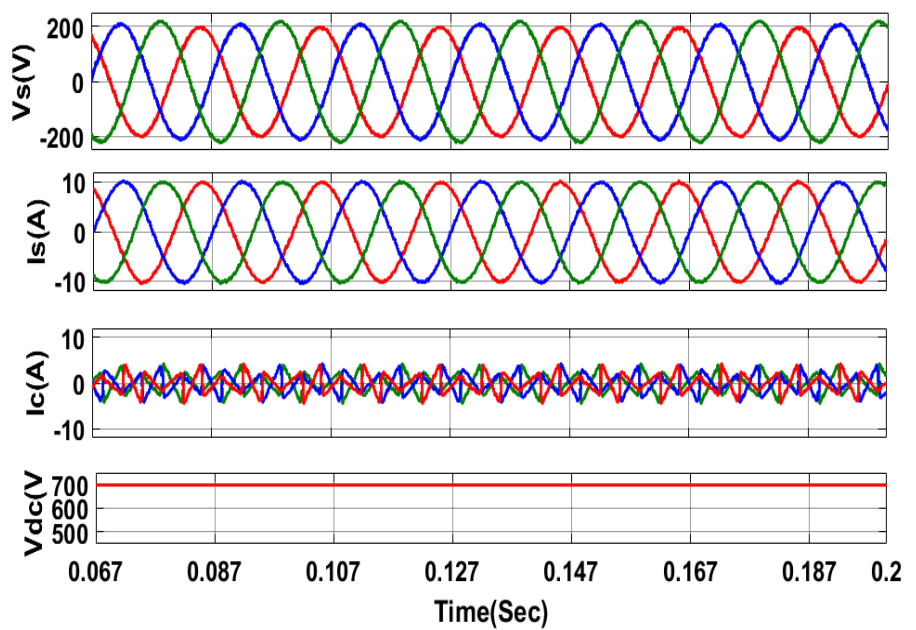


\section{Result of FFT Analysis of RL Load}

Figure 15 shows the Fast Fourier Transformation (FFT) analysis of load current before and after compensation. The THD obtained in Figure 15 is $26.68 \%$ and the fundamental $(50 \mathrm{~Hz})$ value is $9.701 \mathrm{~A}$. This THD value is large when compared with the IEEE standard harmonic limit (i.e $<5 \%$ ). The developed SAPF model was subjected to Fast Fourier Transformation (FFT) analysis under balanced voltage with SVPWM. The result obtained in Figure 16 shows the Fast Fourier Transformation (FFT) analysis of load current after compensation. The result shows a significant $1.74 \%$ reduction of THD when compared with $26.80 \%$ in Figure 15. Figure 17 shows the Fast Fourier Transformation (FFT) analysis of load current after compensation with SPWM. The result is within the range of IEEE harmonic standard limit of $5 \%$.

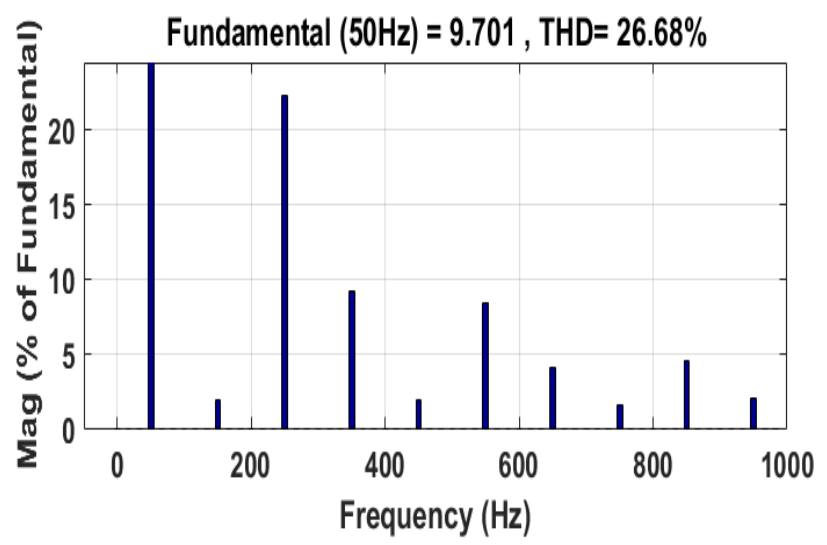

Figure 15: FFT Analysis of Source Current (Is) with RL Load before Compensation.

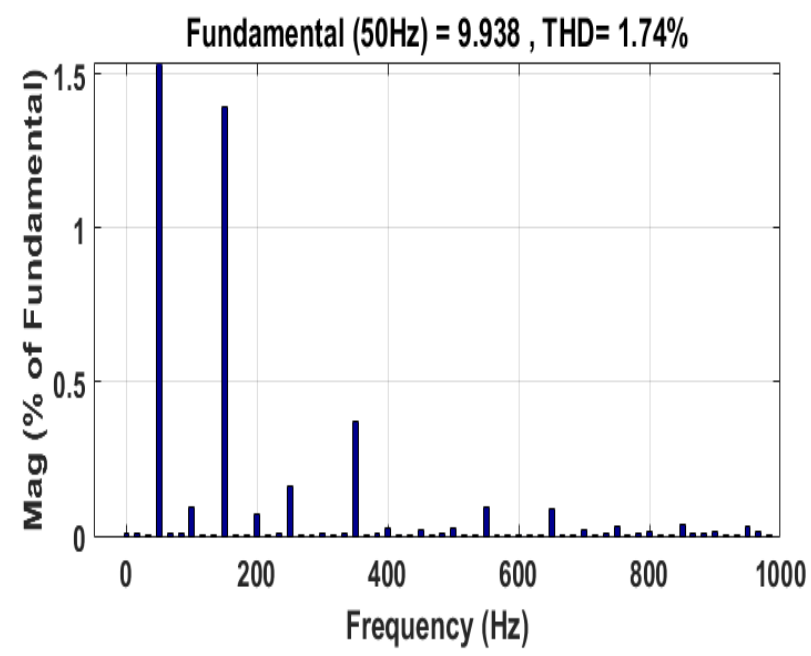

Figure 16: FFT Analysis of the Source Current (Is) after Compensation with SVPWM for RL Load.

\section{CONCLUSION}

Shunt Active Power Filter (SAPF) with Space Vector Pulse Width Modulation (SVPWM) based current control method has been developed for harmonic reduction.

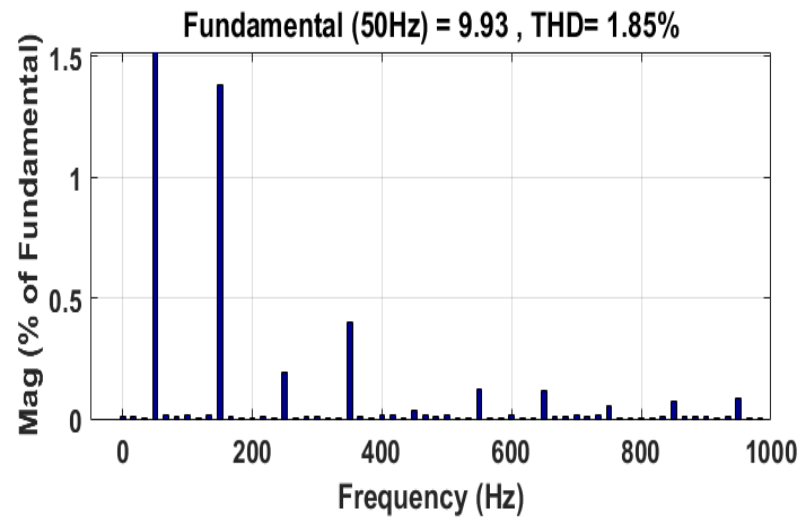

Figure 17: FFT Analysis of Source Current (Is) after Compensation with SPWM for RL Load.

Table 2: Results summary.

\begin{tabular}{|l|c|c|c|c|}
\hline \multirow{2}{*}{ Voltage } & \multirow{2}{*}{$\begin{array}{c}\text { Control } \\
\text { Strategy }\end{array}$} & \multirow{2}{*}{$\begin{array}{c}\text { THD } \\
\text { without } \\
\text { SAPF }\end{array}$} & \multicolumn{2}{|c|}{ THDs with SAPF } \\
\cline { 4 - 5 } & & SVPWM & SPWM \\
\hline Balanced & SRF & 25.60 & 0.91 & 1.13 \\
\hline Unbalanced & SRF & 26.68 & 1.74 & 1.85 \\
\hline
\end{tabular}

Synchronous reference frame theory was used to transform ac in $a-b-c$ quantities into DC in $d-q$ quantities and also as control strategy to extract reference harmonic current. The developed model was tested for both RL load under balanced and unbalanced sinusoidal voltage input. FFT analysis shows that harmonic has been reduction from $25.60 \%$ to $0.91 \%$ (THD) for RL nonlinear load for balanced load and $26.68 \%$ to $1.74 \%$ for unbalanced load using SVPWM. SPWM also reduced harmonic from $25.60 \%$ to $1.13 \%$ under balanced RL load and $26.68 \%$ to $2.47 \%$ under unbalanced RL load. The results show that SVPWM performed better than SPWM. The FFT analysis shows that all the results are within the limit of IEEE 519 standard.

\section{REFERENCES}

Abdeldjabbar, M. K. \& Tayeb, A. (2017). Adaptive Hysteresis Band Based Fuzzy Controlled Shunt Active Power Filter. Paper Presented at International Symposium on Industrial Engineering and Operations Management (IEOM), Bristol, U.K., IEEE Conference, 718-726.

Abhijit, A. I. \& Kompelli, S. (2016). Harmonics Reduction With Id-Id Control Strategy Using Fuzzy Logic Controller Based Three-Phase Shunt Active Power Filter (SAPF). International Journal of Research Publications in Engineering and Technology, 2(5): 10-15.

Akash, N. B. \& Mukund, R. S. (2015). Performance Analysis of Active Power Filter (SAPF) With Different Switching Generation Techniques. International Journal of Science and Research (IJSR), 4(4): 331-336.

Ali, C.; K. F. Mohammed; F. B. Mohamed, \& K. Abdelhalim. (2015). Sliding Mode Control for Four Legs Shunt Active Power Filter (SAPF) to Eliminate Zero 
Sequence Current, Compensating Harmonics and Reactive Power with Fixed Switching Frequency. Serbian Journal of Electrical Engineering, 12(2): 205-218.

Balasubramaniam, P. M.; S. U. Prabha; T. N. Chennai; \& T. N. Sathyamangalam. (2014). A Practical Approach to Harmonics Compensation in Electrical Power Systems Using Shunt Active Power Filter (SAPF). International Journal of Soft Computing, 9(3): 160-168.

Chelli, Z.; R. Toufouti; A. Omeiri; \& S. Saad. (2015). Hysteresis Control for Shunt Active Power Filter (SAPF) Under Unbalance and Three-Phase Load Condition. Journal of Electrical and Computer Engineering, 2015: 1-10.

Chennai, S. \& Benchouia, M. T. (2011). Intelligents Controller for Shunt Active Power Filter (SAPF) to Compensate for Harmonics Based on SRF and SCR Control Strategies. International Journal of Electrical Engineering and Informatics, 3(3): 372-393.

Dev, K. T. (2015). Power Quality Improvement Using DVR. M.Sc Thesis, Department of Electrical Engineering, National Institute of Technology, Rourkela.

Hemachandran, K.; P. Nishanth; B. R. Justus; \& S. S. Darly. (2015). Method of Improving Power Quality Using FPGA with SAPF in Power Systems. SSRG International Journal of Electrical and Electronics Engineering (SSRG-IJEEE), 2(10): 8-10.

Irfan, A.; S. Virendra; \& C. Pradeep. (2016). Control Techniques for Active Power Filter for Harmonic Elimination and Power Quality Improvement. International Journal of Electrical, Electronics and Data Communication, 4(10): 2536.

Jin-Woo, J. (2005). Project Number Two Space Vector Pwm Inverter. Ph.D Project, Mechatronic Systems Laboratory Department of Electrical and Computer Engineering. The Ohio State University.

Kumar, P. (2015). Harmonics Elimination and Power Factor Correction Using Space Vector Modulation (SVM). Asian Journal of Current Engineering and Maths, 4(6), 83-87.

Kumar, V. E.; A. B. Arvind; \& M. C. Nilesh. (2015). Self-Tuning Filter Method for Real Time Control of ThreePhase Shunt Active Power Filter (SAPF). International Journal of Engineering Researches and Management Studies, 2(2): 1-6.

Mohammed, K. (2012). Investigation of Shunt Active Power Filter for Power Quality Improvement. M.Sc Thesis, Near East University.

Nalini, C. K.; S. D. Subhransu; \& S. L. Prema. (2011). A Few Aspects of Power Quality Improvement Using Shunt Active Power Filter. International Journal of Scientific \& Engineering Research, 2(5): 1-11.

Naresh, K. \& Prabhat, K. (2012). Hybrid Active Filter Based On SVPWM for Power Conditioning Using Matlab/Simulink Toolbox Environment. International Journal of Electronic and Electrical Engineering, 5(2): 113-133.

Niklesh, D. \& Sandeep, M. (2017). Power Quality Improvement of Three-Phase System Using Shunt Active Power Filter (SAPF). International Journal of Innovation
Research in Electrical, Electronics, Instrumentation and Control Engineering, 5(3): 23-26.

Phuong, H. T. (2012). Matlab/Simulink Implementation and Analysis of Three Pulse-Width-Modulation (PWM) Techniques. M.Sc Thesis, Boise State University.

Priyanka, S. S \& Shruti, G. (2017). Implementation of shunt active power filter with comparative study of SPWM and SVPWM technique for reduction of THD. International. Journal of Engineering Research and Application, 7(9): 4247.

Rahul, K. G. (2014). Implementation of Shunt Active Power Filter (SAPF) Algorithms. B.Tech. Thesis, Department of Electrical Engineering, National Institute of Technology, Rourkela.

Renu, S.; K. G. Deepak; and S. Harpreet. (2016). Analysis of Space Vector PWM for ThreePhase Inverter and Comparison with SPWM. International Journal of Advanced Research in Electrical, Electronics and Instrumentation Engineering, 5(1): 533-540.

Saravana, P. \& Balachrishnan, P. A. (2014). An Efficient Space Vector Modulation (SVPWM) with BFO Based Self-Tuning PI Controller for Shunt Active Power Filter (SAPF). Research Journal for Applied Sciences, Engineering and Technology, 7(20): 4281-4295.

Sindhu, M. R.; G. N. Manjula; \& T.N. Nambiar. (2015). Three-Phase Tuned Shunt Hybrid Filter for Harmonic and Reactive Power Compensation. Elservier Procedia Technology, 21: 482-489.

Soomro, D. M.; M. A. Omran; \& S. K. Alswed. (2015). Design of Shunt Active Power Filter (SAPF) to Mitigate the Harmonics Caused by Non-Linear Loads. APPN Journal of Engineering and Applied Sciences, 10(19): 87748782 .

Suleiman, M.; A. M. Mohd; H. Hashim; I. A. Noor; H. Yap \& A. A. Mohammad. (2017). Modified Synchronous Reference Frame (SRF) Based Shunt Active Power Filter (SAPF) With Fuzzy Logic Pulse Width Modulation (FLC-PWM) Inverter. Energies 2017 Journal, 10(785); 1-17.

Sunitha, M., \& Kartheck, B. N. (2013). Elimination of Harmonics Using Shunt Active Power Filter (SAPF) Based on D-Q Reference Frame Theory. International Journal of Engineering Trends and Technology (IJETT), 4(4): 781-785.

Suresh, M. \& Anup, K. P. (2011). Id-Iq Control Strategies for Mitigation of Current Harmonics with Fuzzy Logic Controller using Matlab/Simulation and RTDS Hardware. Intelligent Control and Automation, 2: 371-382.

Tej, K. R. \& Ruchi, P. (2014). Space Vector Modulation and Maximum Power Tracking Control on Photovoltaic Power Generation System. Paper presented at 11th IRF International Conference, Pone, India, 59-63.

Thamizhazhagan, $P$ \& Sutha, $S$ (2015). Analysis of PWM Techniques for Power Quality Improvement in PMSM Drives. Indian Journal of Science and Technology, 8(24): 1-5.

Umar, B. M. (2017). Modeling and Simulation of Compact Fluorescent Lamp for the Analysis and Mitigation of Harmonics Injection into Power Distribution Network. 
M.Sc Thesis, Department of Electrical and Computer Engineering, Ahmadu Bello University, Zaria, Nigerian.

Varaprasad, O. V. S. R., \& Sarma, D. S. (2014). An improved SVPWM based shunt active power filter for compensation of power system harmonics. In 2014 16th International Conference on Harmonics and Quality of Power (ICHQP), 571-575.

Venkata, B. S.; B. B. Mahesh; L. S. Ravi \& S. S. Tulasiram. (2014). Design of Shunt Active Power Filter (SAPF) for Improvement of Power Quality with Artificial Intelligence Techniques. International Journal of Advance Research in Electrical, Electronics and Instrumentation Engineering, 3(8): 11304-11314.
Zahira, R. \& Peer, A. F. (2012). Technical Survey on Control Strategies of Shunt Active Power Filter (SAPF) for Harmonics Suppression. Elsevier Procedia Engineering (30): 686-693.

Zulkifilie, B. I.; M. L. Hossain; I. B. Bugis; N. M. N. Mahadi \& S. A. Ahmad. (2014). Simulation Investigation of SPWM, THIPWM and SVPWM Techniques for Three Phase Voltage Source Inverter. International Journal of Power Electronics and Drive System, 10(10): 1-10. 